\title{
Life cycle assessment of manufacturing processes of a headrest in Morocco.
}

\author{
Errouame Mohammed, Amrani Mahacine. \\ Laboratory of Chemical Engineering and Resource Valorisation, \\ AbdelmalekEssaadi University, Faculty of Sciences and Technology, Tangier, Morocco. \\ Mohammed.errouame@gmail.com,+212673734585.
}

\begin{abstract}
Actually, the world's car production is constantly on the increase. Approximately 2.9 cars are produced and sold every second, which is mainly linked to the strong demand for cars in a flourishing market all over the world. Nowadays, the car stands for an essential tool in the daily life of man (vehicle sales in world markets reached 90.68 million in 2015 and 89.7 million in 2014). Consequently, there has been rapid growth in terms of the implantation of automotive production plants with a view to meeting the market needs. However, this very motor vehicle production currently faces huge challenges, the most important of which are related to environmental issues and how manufactures can produce a sustainable and profitable industry for the future (through adopting more environmentally-friendly technologies such as the use of more sustainable fuel resources and new types of modular design with built-in reclability).Our study will mainly emphasize life cycle assessment (LCA) of a headrest for an automotive seat in Morocco. That is to say, this study is based upon the requirements of the ISO 14040 standards by means of OpenLCA software. Besides, this study aimed at evaluating the environmental impacts while adopting the CML 2001methodology in order to assessing the impacts of the manufacturing process of a headrest (raw material, cutting, sewing and injection). Therefore, this study will enable us to evaluate different environmental impacts, including ecology, toxicology, ecotoxicology and the depletion of natural resources. What is more, system boundary was fixed on the product manufacturing process (ranging from receipt the raw material to the final product) and the functional unit was selected as 1 headrest. As it turns out, the greatest environmental impact has been associated with the injection process, but, on reflection, we concluded that the manufacture of headrests for a car has negative environmental impacts. Accordingly, this study can be generalized with the aim of evaluating the impact of any headrest being manufactured anywhere in the world.
\end{abstract}

Keywords: Life Cycle Assessment, Headrest. Automotive industry, Impact assessment. Environmental impact, ISO 14040.

\section{INTRODUCTION}

Year after year, the world car production is increasing in an evident way. Around 2.9 cars are being produced and sold every second [1]. Also, the Moroccan automotive industry has grown to sustained levels of growth over the past decade. The logic of ecosystems favours a more marked integration of the sector, along with a better organization of its players who gain in competitiveness, quality and responsiveness. Five ecosystems have been set up to date in the automotive sector. That is to say, they include automotive wiring, car and vehicle interior, metal and stamping, automotive batteries, trucks and industrial bodies, and engines and transmissions. [3] The automobile seat manufacturing industry has an important role, especially in 2014 as the sector had more than 150 factories in three main regions: Tangier (43\%), Casablanca (39\%) and Kenitra (7\%), which makes possible to cover the main trades with the aim of generating high value-added vehicle equipment [4]. It includes the manufacturing industries for head restraints for car seats, which stands for an essential component in the car seat to maintain the driver's head or passenger. It forms the upper part of the car seat, its main function is to protect the head and upper spine in case of accidents, in that it has an additional advantage which revolves around the comfort of the people by providing support for their heads by means of the head restraint [5].

Every single industry or industrial plant is an environment. It can be consideredas an emitting medium (inputs): raw material, consumable material, energy and water, or a receiving medium (outputs): releases to air, waste, wastewater and noise pollution, which represents the environmental impact of industrial activity.

The Life Cycle Assessment (LCA) methodology is an efficient tool for studying, assessing and quantifying the environmental impacts of products (whether they are goods, services or manufacturing processes) in their life cycles, from extraction of raw materials to end-of-life disposal (recovery, recycling, landfilling). 
In this context, our study made a life-cycle assessment of a head restraint in its manufacturing in Morocco. Life cycle assessment (LCA) methodology was adopted through the production stages of a head restraint which starts with the reception of the raw material, subsequently the cutting, sewing and injection process. We abided by the steps required by the ISO 14040 series. We adopted the CML 2001 method, database Ecoinvent and the OpenLCA software with the aim of evaluating and quantifying the environmental impacts. In order to figure out which was the most important environmental impacts from cradle to gate associated with the fabrication process.

\section{MATERIALS AND METHODS}

In the study, LCA methodology was applied to assess the potential environmental impacts in the life cycle of a headrest. Therefore, this methodology was used to evaluate and analyze the potential environmental aspects and impacts of a product throughout its life cycle. [8] The study was carried out in accordance with the requirements of the ISO 14040/44 series, which defines four principal stages: definition of the objectives and scope of the study, life cycle inventory analysis, environmental impact assessment and interpretation stage. All data collected were modelled by OpenLCA v1.3.4 [9], [10], using the Ecoinventdatabase [11], [12] and then the CML 2001 method was adopted for the assessment of the different environmental impacts generated.

\section{A. Life cycle assessment}

Life Cycle Assessment (LCA) has developed rapidly in recent decades a technique that systematically allows to identify the resource flows and environmental impacts in relation with the provision of products and services. Previously, Life Cycle Assessment (LCA) has been practiced since the early 1970s to assess the environmental impact of any product, either goods or services, throughout its life cycle [6]. For the sake of introducing a universal technique that could be widely used to address potential environmental effects associated with a product, the International Organization for Standardization (ISO) has introduced the principles, framework and basic requirements for managing each product phase of LCA in 1997 [7]. In the late 1990s, ISO developed the four phases of the LCA, which encompasses the definition of objectives and scope of the study, Life Cycle Inventory Analysis (LCI), Life Cycle Impact Assessment (LCIA)) and interpretation, which were subsequently revised and replaced by two shorter but more succinct documents, from ISO 14040 to ISO 14044[7]. The ISO standard has provided a precise definition for LCA: Life Cycle Assessment is a technique for assessing environmental aspects and the potential environmental impacts of a product (cradle to grave), from the acquisition of the raw material to its production, use and destruction.

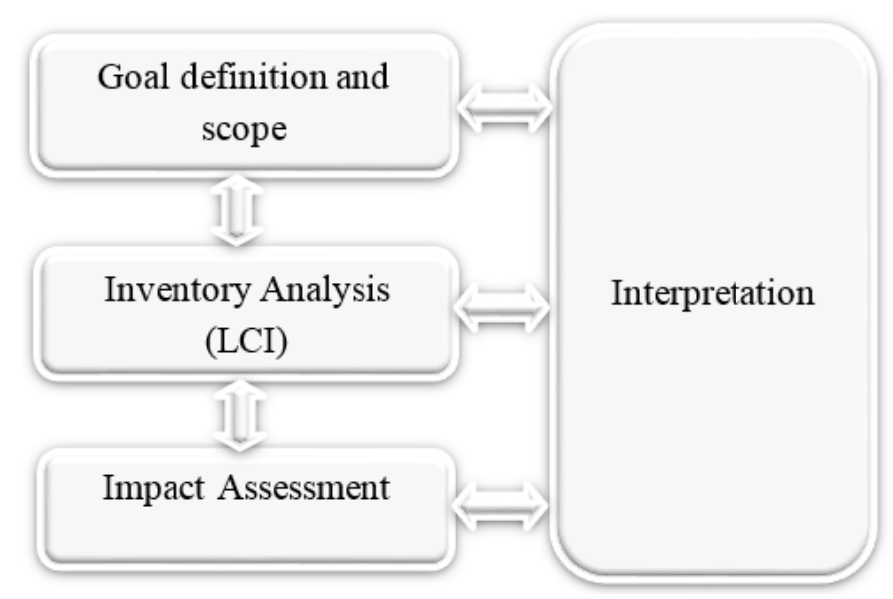

Fig.1. Life cycle assessment (LCA) structure

As it has already been mentioned, the life cycle assessment methodology based on four main steps, figure "1". Among the objectives of life cycle analysis are the assessment of the environmental aspects and impacts of any product, service or process regarding the environment, in order to achieve the objective of providing assistance in terms of the product or process that leads to a minimum effect on the environment. Besides, the LCA gives a global view on the life cycle of a product, the displacement of ecological and environmental impacts (pollution transfer) between the different stages or between particular processes that can be identified and avoided. In short, users can use LCA for eco-design of a product and for cost estimation.

\section{B. Goal definition and scope}

The definition of the objectives and fields of the study is perhaps the most important phase of a Life Cycle Analysis (LCA). The study is carried out according to the statements made therein, which defines the aims of the study, the product to study, the limits and boundaries of the system, the functional unit (FU) and assumptions of the study. [13] The purpose of FU is to lay the groundwork for providing a reference unit to 
which the inventory data is standardized. In other words, the definition of FU depends on the category of environmental impact and the objectives of the survey and must be clearly defined as it serves as a basis for determining the boundaries of the system to be studied, they are often illustrated by an input and output diagram of all operations which set out at the level of the product lifecycle, process or activity.

\section{Life Cycle Inventory Analysis (LCI)}

It is considered as the most intensive phase in comparison to other phases in a Life Cycle Analysis (LCA), mainly by virtue of data collection. The life cycle inventory points out the identification and quantification of the inputs and outputs of each elementary process according to the reference flow. In consequence, it is an inventory of elementary flows (energy and materials) and emissions (pollutants, waste, water discharges, etc.) [14]. The evaluation of the quality of the LCI datasets is an important step for Life Cycle Analysis (LCA). For achieving this very intended result, two methods are possible: a qualitative method according to indicators and a quantitative method by calculating the uncertainty linked to the data [14].

D. Impacts Assessment (or Life Cycle Impacts Assessment (LCIA))

The Life Cycle Impacts Assessment (LCIA) is designed to understand and assess all potential environmental impacts which are based on inventory analysis, within the scope and objective of the study. In this phase, the results of the inventory are attributed to different categories of impact, in relation to the types of impacts expected on the environment. The impact assessment of LCA consists of the following elements: classification and characterization, and optional elements: standardization, weighting grouping and data quality analysis [6]. Classification is the process of attributing the LCIA results to the selected impact categories [15]. Characterization can be defined as the assessment of the magnitude of the potential impacts of each inventory flow in its corresponding environmental impact. Weighting: Conversion and eventual aggregation of indicator result in impact categories using numerical factors based on value choices. Data quality analysis: better understanding of the reliability of the set of indicator results and the profile of the impact assessment [16].

\section{E. Interpretation}

The interpretive stage is composed of making various analyses at different levels that can back up a decision or can provide an easily understandable result of a Life Cycle Assessment (LCA). It must meet the objectives of the study identified in the first step with the intention of proposing recommendations which are appropriate to them. At this stage, it is also of paramount significance to identify the relevant solutions for redesigning the product according to the quality of the data. It is therefore about analyzing the results, complete control, sensitivity check and consistency check [6].

\section{A. Goal definition and scope}

\section{RESULTS}

The objective of the study was to evaluate the environmental impacts of the manufacturing industry of head restraints in Morocco, to compare the associated impacts with sub-processes and to distinguish the most polluting category.

The process of manufacturing headrests goes through a number of stages. The first step is about the receipt of the raw material, then the stages of production. The frontier of the study system constitutes the stages of production and encompasses the transport of the raw material (figure 2) 


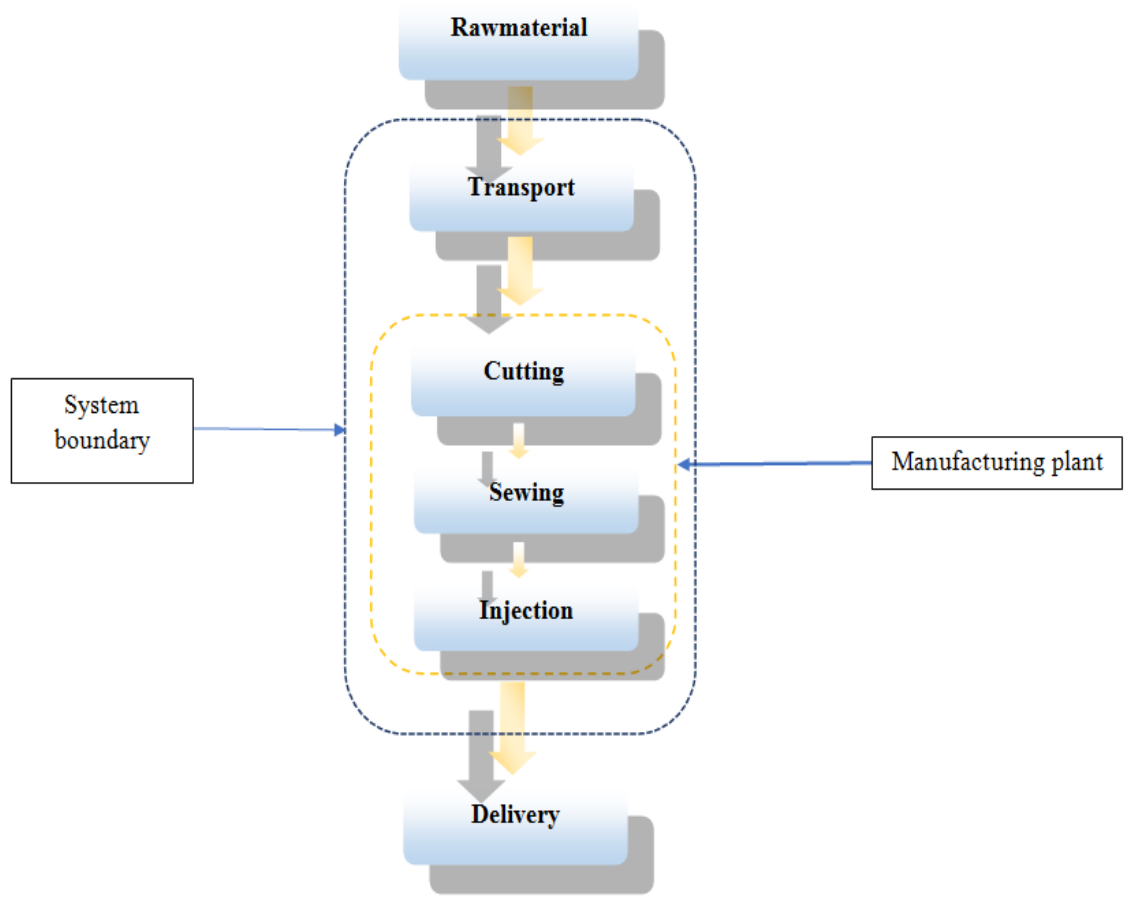

Fig. 2. Production diagram of the caps and head restraint

The manufacturing process begins by the process of cutting. This process takes care of the cutting of textile and mattresses in panels in addition to the model types which are made on automatic cutting machines. The cutting elementary product is located as an input for the sewing process. The sewing process consist in an assembling of two or more pieces by means of a thread, using a sewing machine or an over locker to make a sewn cap. Comes the injection in which the preparation phase corresponding to the insertion of a rod, the EPP (expanded polypropylene), in addition to a nozzle provided for the injection of the foam by robot. The latter allows the pouring of a mixture of two chemicals, Isocyanate and Polyol via an injection head. These compounds rapidly form, at the level of the cap for ultimately getting a headrest.

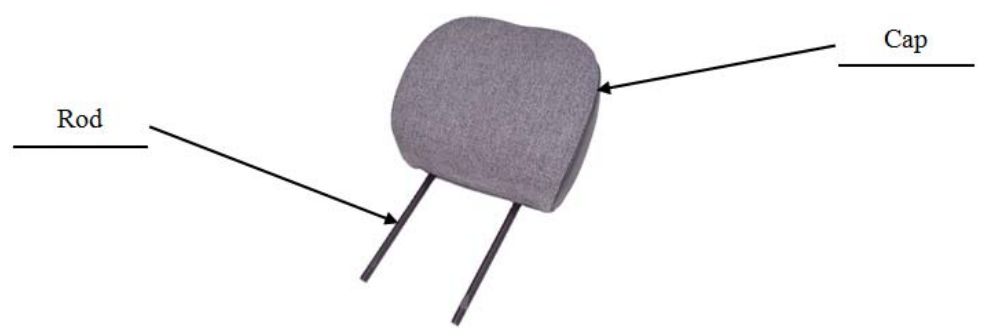

Fig. 3. Example of a headrest

As it has been established by ISO 14044: 2006, We consider functional unit as one headrest which presents the final product of the studied system (Figure 3). the boundaries of the system were assigned as: the product manufacturing. Upstream processes, transportation and production processes were included within the system boundary. The upstream processes are raw materials and energy. Thus, transport means the transport of raw materials and auxiliary materials to the production unit (Figure2).

\section{B. Life Cycle Inventory Analysis (LCI)}

According to the general framework provided by ISO 14040, the analysis of the inventory was accomplished from gate to gate with a view to quantifying the environmental inputs and outputs of the studied system. Our database was collected from a comprehensive study and survey, that's why an inventory was made to collect information regarding raw materials, quantities, kinds and transport category used to transport the material from the suppliers to the manufacturing plant. Consequently, we have estimated the electrical energy consumed for the production, as well as the wastes generated in each step of the process. The results are shown in the table 1. Information as to the material, energy, transport and auxiliary materials was obtained from the plant and the modelling was derived from the inventories in the Ecoinventdatabase.

We dehusked the head restraint with a view to getting to know its component material. We found out that the headrest consists of four elements, the cap, stem, EPP and polyurethane foam (figure 4). 


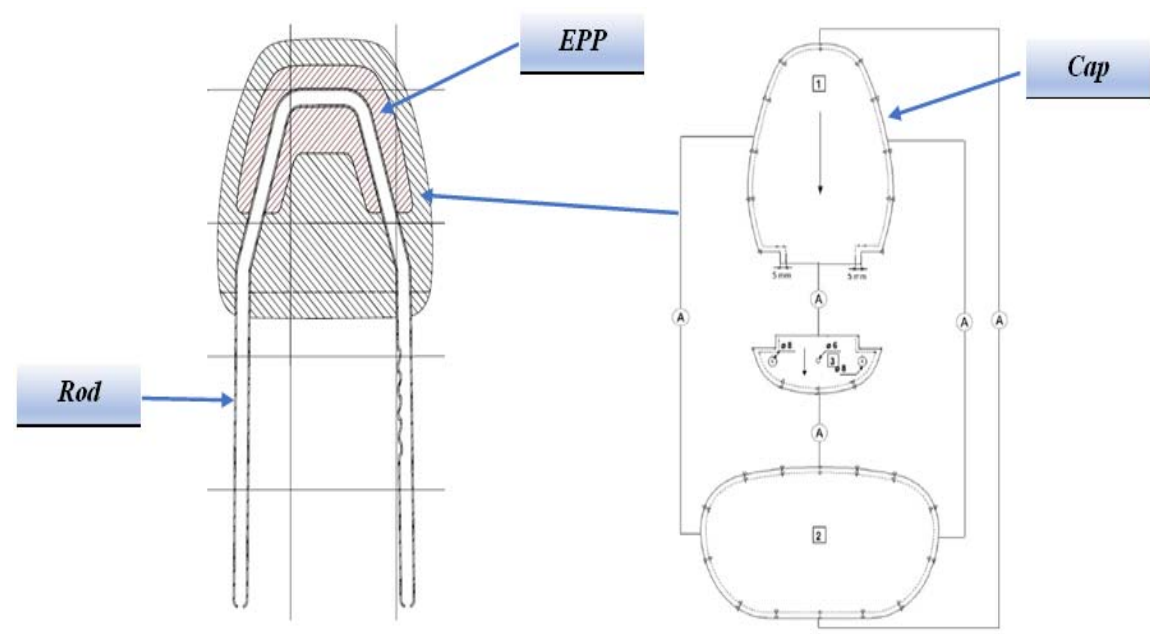

Fig.4. Composition of the headrest

We then estimated and quantified, making use of a field study, the quantity of each material that made up a headrest and the nature of each composition(table I).

Table I Composition for producing a headrest.

\begin{tabular}{|c|c|c|c|}
\hline Description of material & Nature & Amount & Unit \\
\hline Textile & Fabric & 0,082075 & $\mathrm{~m}^{2}$ \\
\hline TEP & Vinyl & 0,073224 & $\mathrm{~m}^{2}$ \\
\hline Thread & Thread & 5 & $\mathrm{~m}$ \\
\hline Polyol & Chemical product & 0.155 & $\mathrm{~kg}$ \\
\hline Isocyanat & Chemical product & 0.106 & $\mathrm{~kg}$ \\
\hline Nozzel & Plastic & 1 & $\mathrm{P}$ \\
\hline EPP & Plastic & 1 & $\mathrm{P}$ \\
\hline Rod & Metal & 1 & $\mathrm{P}$ \\
\hline
\end{tabular}

Seeing that transport represents an integral part of our system, we have made an inventory of the types of transport which are used for transporting the raw material from the supplier to the manufacturing plant, including the cost of transport (the journey) and distance travelled(table II).

Table II Type of transport and distance traveled to transport the raw material.

\begin{tabular}{|c|c|c|}
\hline \multirow{2}{*}{ Raw material } & \multicolumn{2}{|c|}{ Distance } \\
\cline { 2 - 3 } & Maritime (km) & Road (km) \\
\hline Textile & 41 & 759 \\
\hline TEP & 41 & 759 \\
\hline Thread & 41 & 2639 \\
\hline Polyol & 41 & 2399 \\
\hline Isocyanat & 41 & 2399 \\
\hline Nozzel & 41 & 3450 \\
\hline EPP & 41 & 1109 \\
\hline Rod & 10822 & 81 \\
\hline Total & $\mathbf{1 1 1 0 9}$ & $\mathbf{1 3 5 9 5}$ \\
\hline
\end{tabular}

An inventory has been set up for each process. Besides, we have defined the inputs and outputs (elementary product and generated waste). As a result, we have Analysed the flow of materials as illustrated in figure 5 . 


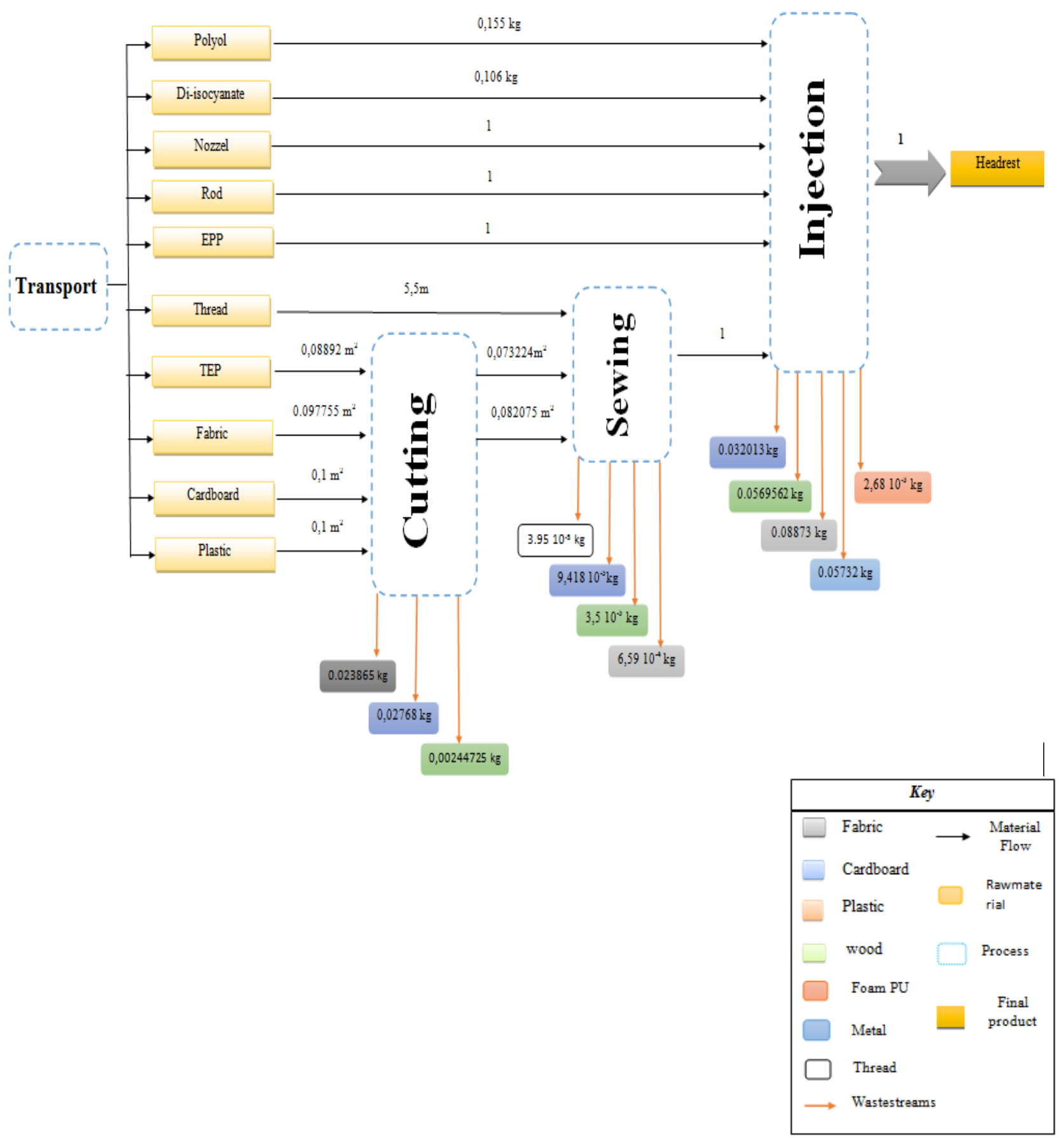

Fig 5. Material flow for the manufacture of a Headrest.

\section{Impacts Assessment (or Life Cycle Impacts Assessment (LCIA))}

In the study, we have adopted the method CML 2001 in the (Life Cycle Impact Analysis) LCIA phase. Moreover, this method abides by the standardization procedure for impact assessment. In other words, in this method, environmental impacts are calculated in four stages: classification, characterization, standardization and evaluation. In addition to that, it represents a method for calculating problem-oriented indicators, which cover several impact categories (17).

In our framework, it is recommended to focus on global and regional impacts, impacts such as toxicity or ecotoxicity, which are to give an idea of location. Accordingly, the list of the selected impacts in the study is the following: resource consumption, climate change, degradation of the ozone layer, eutrophication, aquatic and terrestrial toxicity and ecotoxicity. The results of the simulation show in:

- Figure 6 shows the impact for each process of the fabrication as cutting, sewing and injection included the transportation of raw materials.

- Figure 7 shows the hot spot category impact of the input elements that is included in System boundary. 


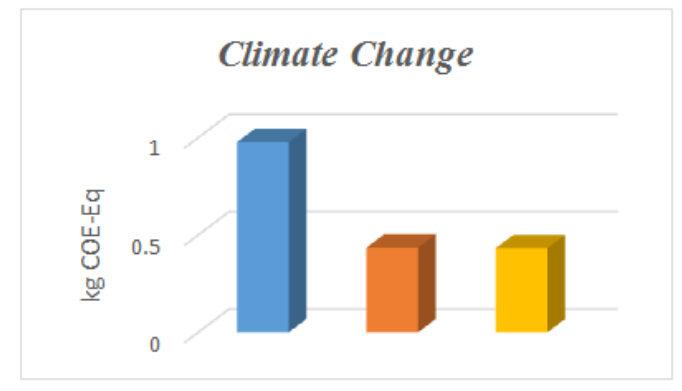

(a) $\mathrm{CC}$

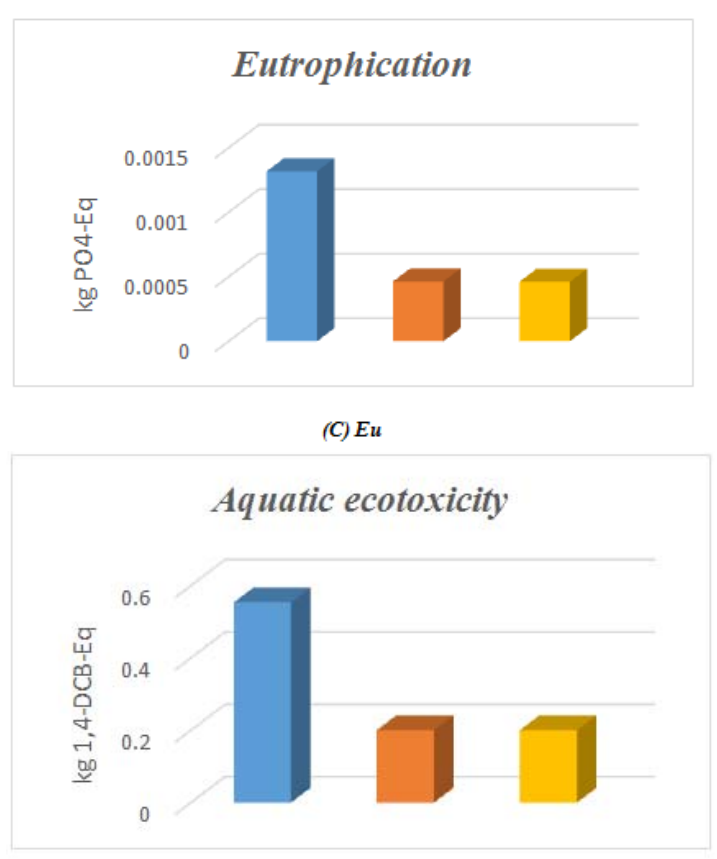

(e) $E A$

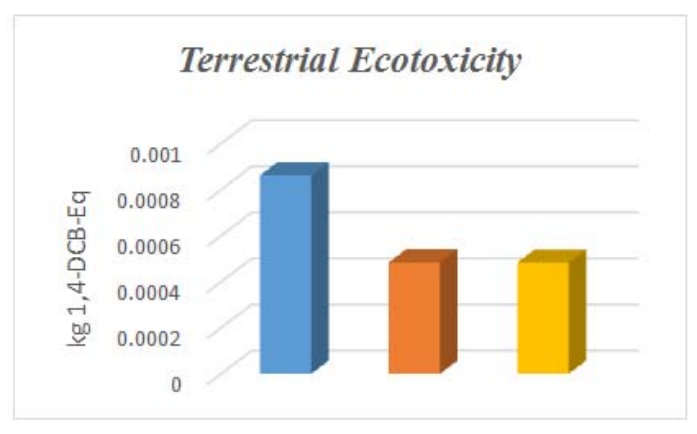

(g) $E T$

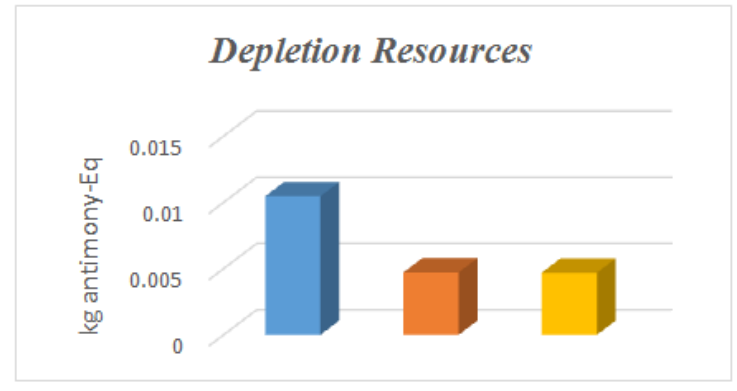

(b) $E R$

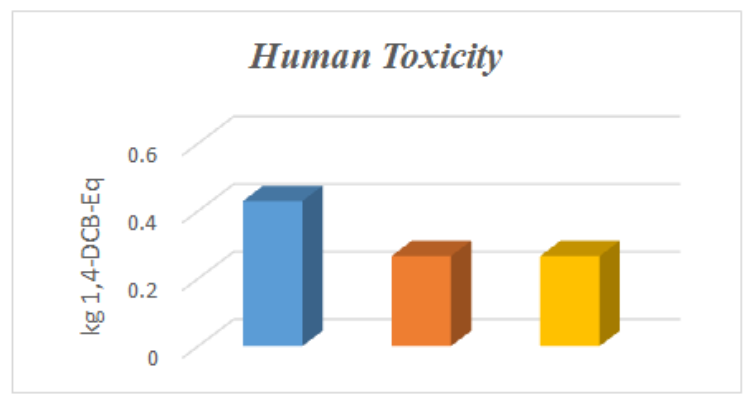

(d) $T$

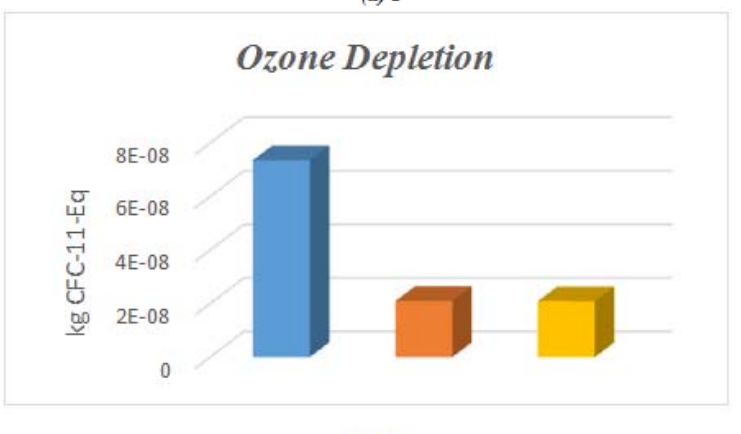

(f) $\mathrm{CO}$

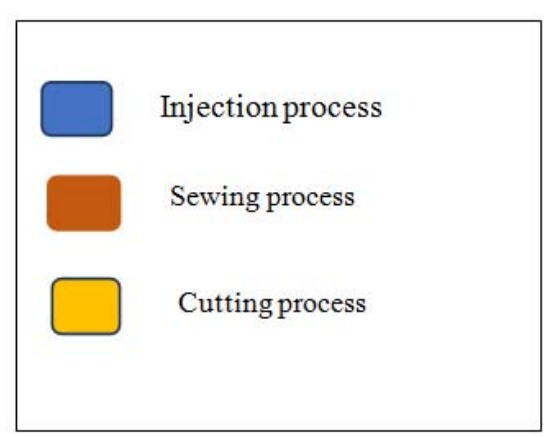

Fig. 6. The impacts of the manufacturing process of a headrest 

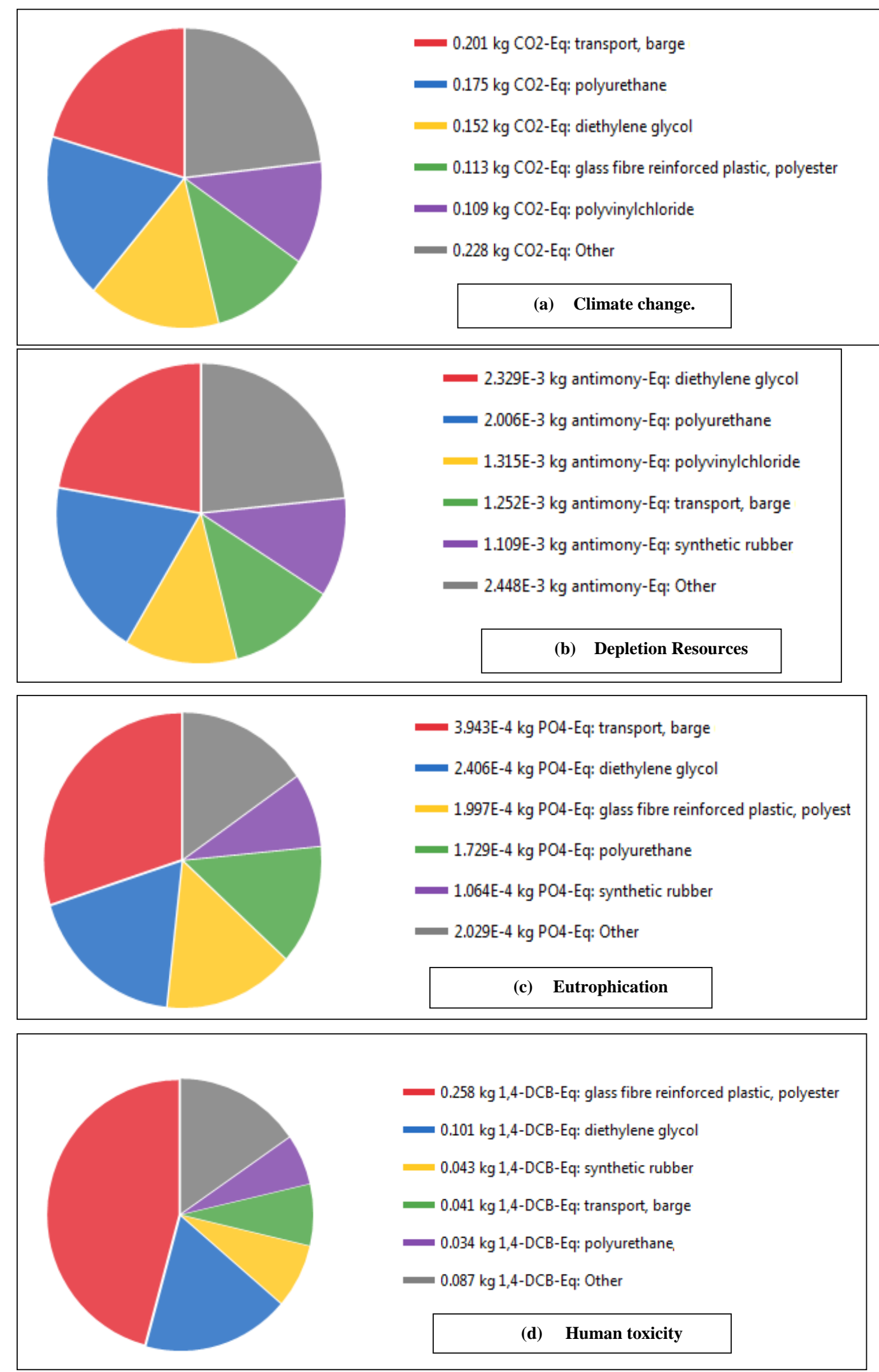

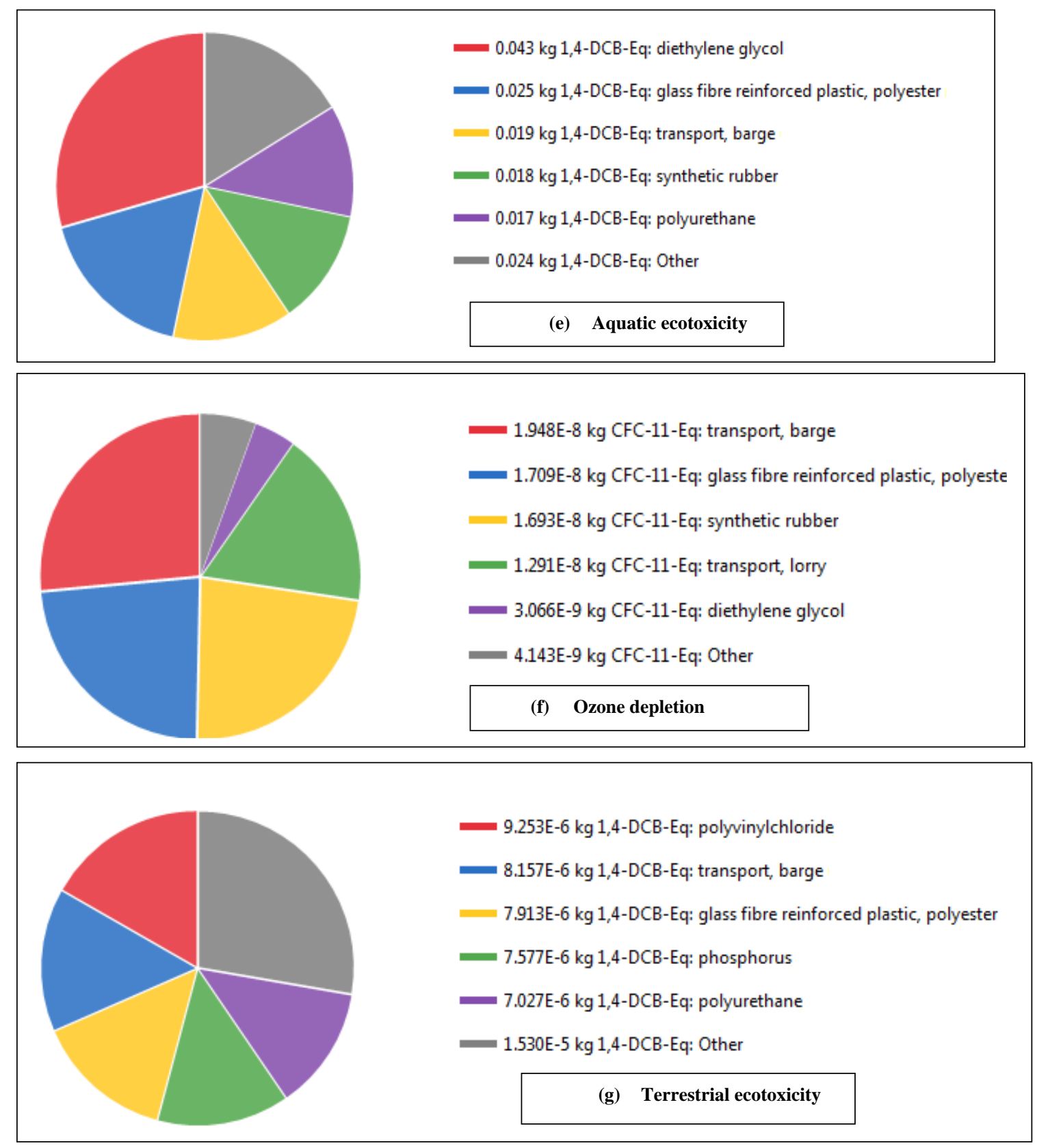

Fig. 7. The hot spots category impact in manufacturing process of a headrest

\section{D. . Interpretation}

Figure 6 shows the environmental impacts of each process of manufacturing a head restraint: cutting, sewing and injection. The injection process has the greatest impact in different categories, such as:

- Climate change has an impact of about $0.97 \mathrm{Kg} \mathrm{CO} 2-\mathrm{Eq}$,

- Resource depletion: $0.0104 \mathrm{~kg}$ antimony-Eq,

- Eutrophication: $0.0013 \mathrm{~kg}$ PO4-Eq

- Toxicity: $0.429 \mathrm{~kg} 1,4-\mathrm{DCB}-\mathrm{Eq}$

- Aquatic Ecotoxicity: :0.553 kg 1,4-DCB-Eq

- Degradation of the ozone layer: 7.36E-08 kg CFC-11-Eq

- Terrestrial Ecotoxicity: $0.00086 \mathrm{~kg}$ 1,4-DCB-Eq.

And for the other manufacturing processes cutting and sewing almost express the same values of the environmental impacts in the different categories. 
Figure 7 shows the environmental impacts by input elementary and that the transport of the raw material, polyurethane in addition to the compositions of plastics used represent the most important part of the impact considered. Then comes the production and use of polyurethane and finally the plastics used.

\section{Discussion:}

As far as the other manufacturing processes are concerned, both cutting and sewing process express approximately the same values of the environmental impacts in the different categories. The most important impact in the considered system boundary are the transportation, polyurethane and plastics.

This study has reached the intended aim as it allows to fully understand the environmental impacts at each stage of production and manufacture of a head restraint and to specify the most important stressors. On top of that, it was possible to observe that:

- The most impacting process for a headrest production that is the injection because of the use of chemicals polyol and di-isocyanate, metal (Rod) and also plastic materials.

- The important impact generated by the input/output elements included in the manufactory process, is the transportation as all raw materials are imported from far and others country. flowed by the polyurethane which represent the important componentof the headrest and finally the plastics.

- The most significant categories of impacts are climate change, ecotoxicity and toxicity. Table III The impact values for each category for the manufacture of a head restraint

\begin{tabular}{|l|c|c|}
\hline \multicolumn{1}{|c|}{ LCIA Category } & Value & Unit \\
\hline Toxicity & 0.64891066 & $\mathrm{~kg} 1$,4-DCB-Eq \\
\hline Resource depletion & 0.0195112 & $\mathrm{~kg}$ antimony-Eq \\
\hline Ozone depletion & $9.2779 \mathrm{E}-08$ & $\mathrm{~kg} \mathrm{CFC}-11-\mathrm{Eq}$ \\
\hline Ecotoxicity Aquatic & 2.42281917 & $\mathrm{~kg} 1,4-\mathrm{DCB}-\mathrm{Eq}$ \\
\hline Eutrophication & 0.00300546 & $\mathrm{~kg}$ PO4-Eq \\
\hline Climate change & 1.89742236 & $\mathrm{~kg} \mathrm{CO}-\mathrm{Eq}$ \\
\hline Ecotoxicity Terrestrial & 0.0127691 & $\mathrm{~kg} 1,4-\mathrm{DCB}-\mathrm{Eq}$ \\
\hline
\end{tabular}

The table III stands for the lifecycle analysis of impacts at the end of the manufacturing cycle of a head restraint, from the receipt of the raw materials to the final product (to gate) including transport. It turns out that the automotive industry has a set of impacts on the environment in the production and manufacturing phase as shows figure 8 .

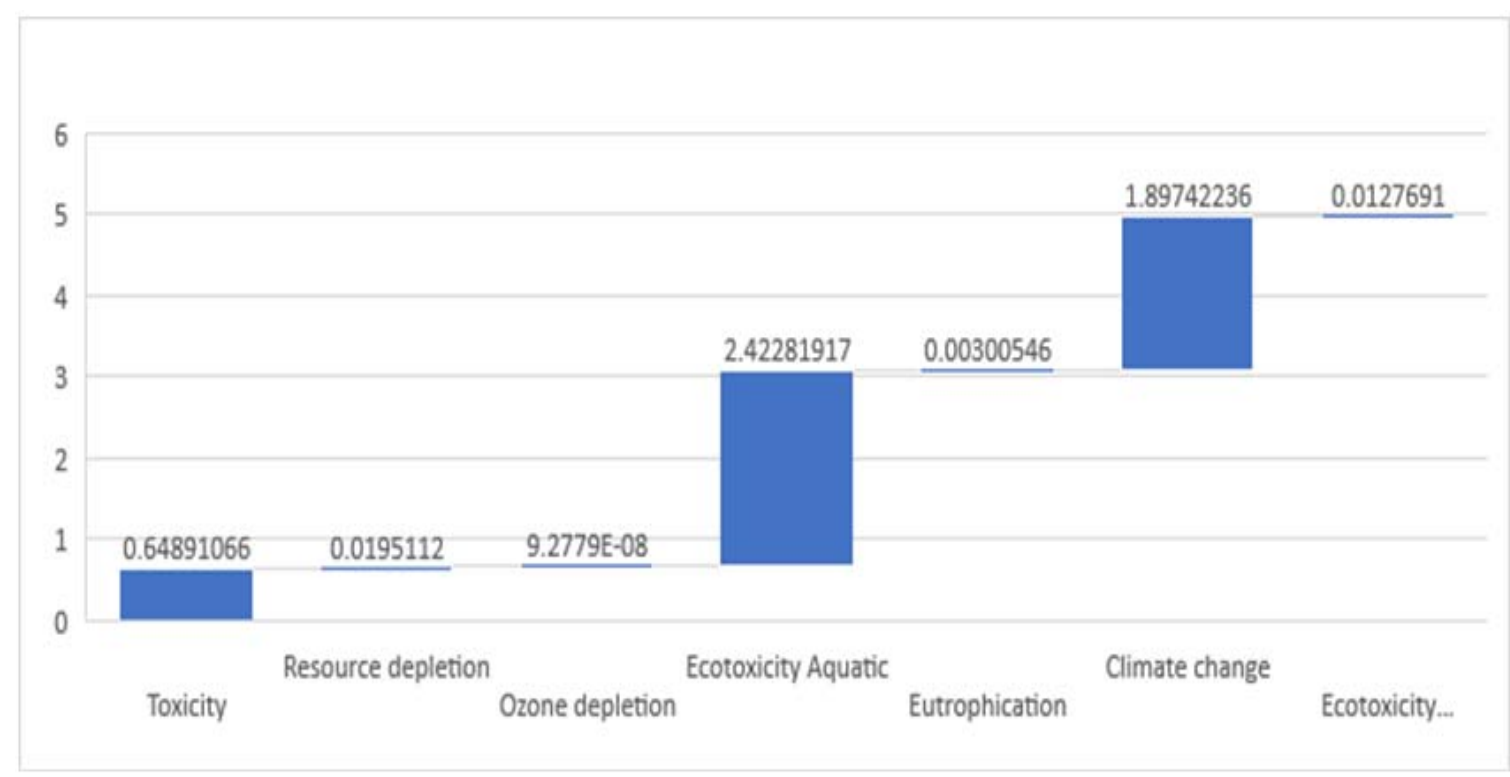

Fig.8. Global impact of manufacturing a head restrain 


\section{CONCLUSION}

The goal of the study is to get through an environment impact assessment of a manufacturing ahead restraint on the environment, using the LCA methodology. Accordingly, the results show the impact value for the various categories such as resource consumption, climate change, ozone depletion, eutrophication, aquatic and terrestrial toxicity and ecotoxicity. It also draws a comparison between the different manufacturing processes and shows which step is mainly stressing the whole production.

The study shows that the most important impact is generated by the injection process, followed by the sewing and cuttingstep in different impact categories. This has allowed us to define the hot spots category which is the transport, polyurethane and the other componentsof the headrest.

Life cycle assessment from the cradle to grave of the manufacturing of a car head rest will complete this study and make possible the evaluation of environmental impacts of car industry.

\section{REFERENCES}

[1] "Planetoscope - Statistiques : Production mondiale de voitures." [Online]. Available: https://www.planetoscope.com/automobile/76production-mondiale-de-voitures.html. [Accessed: 24-May-2017].

[2] "Production Statistics | OICA.” [Online]. Available: http://www.oica.net/category/production-statistics/. [Accessed: 24-May-2017].

[3] “AUTOMOBILE | Ministère de l'Industrie, du Commerce, de l'Investissement et de l'Economie Numérique.” [Online]. Available: http://www.mcinet.gov.ma/ mcinetgov/fr/content/automobile. [Accessed: 24-May-2017]

[4] FLANDERS INVESTMENT \& TRADE, "Le secteur de l'Automobile au Maroc.”.

[5] M. Franz a,b, *, A. Durt a, , R. Zenk a, and , P.M.A. Desmet b, "Comfort effects of a new car headrest with neck support."

[6] Walter Kl̈opffer and Birgit Grahl, Life Cycle Assessment (LCA) A Guide to Best Practice. 2014.

[7] J. Ling-Chin $\mathrm{n}$ and, O. Heidrich, A.P. Roskilly, "Life cycle assessment (LCA) - from analysing methodology development to introducing an LCA framework for marine photovoltaic (PV) systems," Jan. 2016.

[8] Jeroen B. Guinée, "Life cycle assessment: past, present and future." [Online]. Available: http://www.rilem.net/images/publis/917db4447994958c78e8f7a51ca2677d.pdf. [Accessed: 31-May-2017].

[9] Andreas Ciroth, "ICT for Environment in Life Cycle Applications openLCA - A new open source software for Life Cycle Assessment." [Online]. Available: https://sci-hub.cc/10.1065/lca2007.06.337. [Accessed: 31-May-2017].

[10] Andreas Ciroth, Sarah Winter, GreenDelta Berlin, “openLCA 1.4 overview and first steps." [Online]. Available: http://www.openlca.org/wp-content/uploads/2015/11/openLCA_1-4_overview_and_first_steps_v1.pdf. [Accessed: 31-May-2017].

[11] “ecoinvent." [Online]. Available: http://www.ecoinvent.org/. [Accessed: 31-May-2017].

[12] Roland Hischier, "ecoinvent le plus complète des bases de données pour des analyses de cycle de vie." [Online]. Available: https://www.ecoinvent.org/files/201104_hischier_le_plus_compl_te_des_bases_de_donn_es.pdf. [Accessed: 31-May-2017].

[13] Poritosh Roy*, Daisuke Nei, Takahiro Orikasa, Qingyi Xu, Hiroshi Ōkadome, and Nobutaka Nakamura, Takeo Shiina *, "A review of life cycle assessment (LCA) on some food products."

[14] Boufateh ben Arari, "Contribution à l'évaluation de la supply chain pour la filière textile : définition de critères de développement durable application de la méthode de surclassement PROMETHEE à l'analyse du cycle de vie d'un tee-shirt." 2011.

[15] "MÉTHODOLOGIE DE l'ANALYSE DU CYCLE DE VIE (ACV) - Éléments obligatoires d'évaluation des impacts." [Online]. Available: http://stockage.univ-valenciennes.fr/MenetACVBAT20120704/acvbat/chap03/co/ch03_280_3-4-1.html. [Accessed: 05-Jun$2017]$.

[16] "MÉTHODOLOGIE DE 1'ANALYSE DU CYCLE DE VIE (ACV) - Éléments facultatifs de l'évaluation des impacts." [Online]. Available: http://stockage.univ-valenciennes.fr/MenetACVBAT20120704/acvbat/chap03/co/ch03_290_3-4-2.html. [Accessed: 05-Jun2017].

[17] G. Herfray, “Contribution à l'évaluation des impacts environnementaux des quartiers," École Nationale Supérieure des Mines de Paris, 2011. 